www.jmscr.igmpublication.org

Index Copernicus Value: 79.54

ISSN (e)-2347-176x ISSN (p) 2455-0450

crossref DOI: https://dx.doi.org/10.18535/jmscr/v7i4.180

\title{
To Study the Outcomes of Supracostal and Infracostal Access Approach in Treating Renal Calculi using PCNL (Percutaneous Nephrolithotomy)
}

\author{
Authors \\ Dr Ashutosh Kesar ${ }^{1}$, Dr Kulbir Singh Jat ${ }^{2 *}$, Dr Amit Suri ${ }^{3}$ \\ ${ }^{1,2}$ Registrar, Department of Surgery, GMC Jammu \\ ${ }^{3}$ Professor, Department of Surgery ASCOMS Jammu \\ *Corresponding Author \\ Dr Kulbir Singh Jat \\ Registrar, Department of Surgery GMC Jammu, India
}

\begin{abstract}
The lifetime prevalence of kidney stone disease is estimated at $1 \%$ to $15 \%$ with the probability of having a stone varying according to age, gender, race and geographical location (Margeret $S$. pearle et al 2007) ${ }^{8}$. In Indian scenario urolithiasis constitutes one of the commonest reason requiring surgical intervention and approximately about 5-7 million patients suffer from calculus disease.

Aims and Objectives: To evaluate two levels of renal access in PCNL one supracostal and other infracostal and will evaluate their outcomes in terms of:

1) Number of access puncture sites required for complete stone clearance

2) Stone clearance rates

3) Safety

4) Efficacy (Stone free status post op KUB)

5) Complications

Materials and Methods: This study entitled "To Study the Outcomes of Supracostal and Infracostal Access Approach in Treating Renal Calculi using PCNL (Percutaneous Nephrolithotomy)" was conducted in the Post-graduate Department of Surgery, Acharya Shri Chander College of Medical Sciences and Hospital, Jammu from $1^{\text {st }}$ Nov 2016 to $31^{\text {st }}$ Oct 2017.

The site of calyceal puncture in supracostal group was superior calyx in 21 (70\%), Middle calyx in 8 $(26.67 \%)$ and inferior calyx in 1 (3.33\%) of patients respectively, while in the infracostal group it was superior calyx in 5 (16.67\%), middle calyx in 12 (40\%) and inferior calyx in 13 (43.33\%) patients respectively

Keywords: probability, urolithiasis.
\end{abstract}

\section{Introduction}

Stone disease has been described since antiquity. Oldest renal stone was described by Shattock in 1905 and was found in an Egyptian Mummy in a tomb dating approximately 4400BC (Modlin M
$1980)^{10}$. The site of stone formation has migrated from lower to upper urinary tract with westernization of global culture.

The lifetime prevalence of kidney stone disease is estimated at $1 \%$ to $15 \%$ with the probability of 
having a stone varying according to age, gender, race and geographical location (Margeret S. pearle et al 2007) ${ }^{8}$. In Indian scenario urolithiasis constitutes one of the commonest reason requiring surgical intervention and approximately about 5-7 million patients suffer from calculus disease.

About $25 \%$ of patients with kidney stones have a family history of kidney stones (Curhan GC et al 1997) ${ }^{1}$.Genetic studies performed by Resnick and co-workers $(1968)^{14}$ and McGeown (1960) ${ }^{9}$ concluded that urolithiasis may be result of a polygenic defect with partial penetrance (Resnick M et al, 19680) ${ }^{14}$; (Mc Geown MG et al, 1960) ${ }^{9}$.

The primary goal of surgical stone management is to achieve maximal stone clearance with minimal morbidity to the patient (James E Lingeman et al, 2007) ${ }^{6}$. Various treatment options available include:

1. Extracorporeal shock wave lithotripsy with or without an indwelling stent;

2. Percutaneous nephrolithotomy;

3. Combination of both techniques as a planned procedure

4. Retrograde ureteroscopic intra-renal stone disintegration using flexible ureteroscope and laser as an energy source

5. Open surgery (i.e. anatrophic or radical nephrolithotomy, sinusoidal pyelolithotomy)

\section{Aims and Objectives}

To evaluate two levels of renal access in PCNL one supracostal and other infracostal and will evaluate their outcomes in terms of:
1) Number of access puncture sites required for complete stone clearance
2) Stone clearance rates
3) Safety
4) Efficacy (Stone free status post op KUB)
5) Complications

\section{Intra operative}

- Bleeding requiring transfusions

- Intra-thoracic complications

- Vascular injuries

\section{Postoperative}

- Haematuria requiring transfusions/Angioembolisation

- Analgesic requirement

- Fever 6. Hospital stay.

\section{Materials and Methods}

This study entitled "To Study the Outcomes of Supracostal and Infracostal Access Approach in Treating Renal Calculi using PCNL (Percutaneous Nephrolithotomy)" was conducted in the Postgraduate Department of Surgery, Acharya Shri Chander College of Medical Sciences and Hospital, Jammu from $1^{\text {st }}$ Nov 2016 to $31^{\text {st }}$ Oct 2017.

The study consisted of

Prospective analysis of cases who underwent PCNL in urology unit II from $1^{\text {st }}$ Nov 2016 to $31^{\text {st }}$ October 2017 and the patients were divided into two groups on the basis of Renal access :

Group- "S" - Supracostal access

Group- "I" - Infracostal access

Following inclusion and exclusion and exclusion criteria were taken into consideration:

\section{Inclusion Criteria}

1) Patients suffering from renal calculi with normal RFTS

2) Any gender

3) Any age

4) Those patients giving valid consent

\section{Exclusion Criteria}

1) Patients with concomitant supra and infracostal access

2) Patients with abnormal anatomy of Kidneys

3) Patients with severe kyphoscoliosis or other skeletal abnormalities

4) Patients with previous thoracic surgeries or PCNL on the ipsilateral side

5) Patients undergoing other surgeries simultaneously being done which could have affected the study

6) Patients with uncorrectable coagulopathies

7) Patients with Non-Functioning kidney due to calcular disease

8) Patient refusal 


\section{Observations}

The present study entitled "To Study the Outcomes of Supracostal and Infracostal Access Approach in Treating Renal Calculi using PCNL (Percutaneous Nephrolithotomy)" was conducted in the Post- graduate Department of Surgery, Acharya Shri Chander College of Medical Sciences and Hospital, Jammu from $1^{\text {st }}$ Nov 2016 to $31^{\text {st }}$ Oct 2017 . It was a prospective study done for a period of one year. The following observations were made:

Table 1 Age Wise Distribution of the Patients

\begin{tabular}{|l|c|c|}
\hline $\begin{array}{l}\text { AGE IN } \\
\text { YEARS }\end{array}$ & $\begin{array}{c}\text { SUPRACOSTAL PCNL } \\
\text { (Number of patients) }\end{array}$ & $\begin{array}{c}\text { INFRACOSTAL PCNL } \\
\text { (Number of patients) }\end{array}$ \\
\hline $0-20$ & 1 & 0 \\
\hline $21-40$ & 8 & 14 \\
\hline $41-60$ & 19 & 12 \\
\hline$>60$ & 2 & 4 \\
\hline TOTAL & 30 & 30 \\
\hline
\end{tabular}

In our study age of patients ranged from 20 to 78 years. Majority of the patients in our series were in their third, fourth and fifth decade of life.

Table 2 Sex Wise Distributions of the Patients

\begin{tabular}{|l|c|c|}
\hline SEX & $\begin{array}{c}\text { SUPRACOSTAL } \\
\text { PCNL }\end{array}$ & $\begin{array}{c}\text { INFRACOSTAL } \\
\text { PCNL }\end{array}$ \\
\hline MALE & 20 & 21 \\
\hline FEMALE & 10 & 9 \\
\hline TOTAL & 30 & 30 \\
\hline
\end{tabular}

In our study, out of 60 patients, $41(68.33 \%)$ were males and 19 (31.67\%) were females.

Table 3 Level of Calyceal Puncture Site

\begin{tabular}{|l|c|c|}
\hline $\begin{array}{l}\text { CALYCEALPUNCTURE } \\
\text { SITE }\end{array}$ & $\begin{array}{c}\text { SUPRACOSTAL } \\
\text { PCNL }\end{array}$ & $\begin{array}{c}\text { INFRACOSTAL } \\
\text { PCNL }\end{array}$ \\
\hline SUPERIOR CALYX & $21(70 \%)$ & $5(16.67 \%)$ \\
\hline MIDDLE CALYX & $8(26.67 \%)$ & $12(40 \%)$ \\
\hline INFERIOR CALYX & $1(3.33 \%)$ & $13(43.33 \%)$ \\
\hline
\end{tabular}

In our study, in the supracostal group desired calyceal entry was made via superior calyx in 21 (70\%), via middle calyx in $8(26.67 \%)$ and via inferior calyx in $1(3.33 \%)$ patients respectively. In the infracostal group desired calyceal entry was made via superior calyx in 5 (16.67\%), via middle calyx in 12 (40\%), via inferior calyx in 13 $(43.33 \%)$ patients respectively.
Table 4 Number of Tracts Being Made for Stone Extraction

\begin{tabular}{|l|c|c|}
\hline $\begin{array}{l}\text { NUMBER OF } \\
\text { TRACTS }\end{array}$ & $\begin{array}{c}\text { SUPRACOSTAL } \\
\text { PCNL }\end{array}$ & $\begin{array}{c}\text { INFRACOSTAL } \\
\text { PCNL }\end{array}$ \\
\hline SINGLE & $27(90 \%)$ & $23(76.67 \%)$ \\
\hline DOUBLE & $3(10 \%)$ & $6(20 \%)$ \\
\hline TRIPLE & 0 & $1(33.33 \%)$ \\
\hline
\end{tabular}

In our study, in the supracostal PCNL single tract was required in $27(90 \%)$ patients and double tract required in $3(10 \%)$ patients respectively. In infracostal PCNL single tract was required in 23 (76.67\%) patients, double tract in $6(20 \%)$ patients and triple tract in $1(3.33 \%)$ patient respectively.

Table 5 Procedural Outcomes

\begin{tabular}{|l|c|c|c|}
\hline $\begin{array}{l}\text { OUTCOME } \\
\text { VARIABLES }\end{array}$ & $\begin{array}{c}\text { SUPRACOSTAL } \\
\text { PCNL }\end{array}$ & $\begin{array}{c}\text { INFRACOSTAL } \\
\text { PCNL }\end{array}$ & $\begin{array}{c}\text { P- } \\
\text { VALUE }\end{array}$ \\
\hline $\begin{array}{l}\text { STONE } \\
\text { CLEARANCE }\end{array}$ & $100 \%$ & $100 \%$ & - \\
\hline $\begin{array}{l}\text { POST - OP } \\
\text { ANALGESIA }\end{array}$ & $2.2 \pm 0.71$ & $1.63 \pm 0.77$ & 0.004 \\
\hline $\begin{array}{l}\text { HOSPITAL STAY } \\
\text { (days) }\end{array}$ & $3.3 \pm 1.1$ & $3.33 \pm 0.88$ & 0.90 \\
\hline $\begin{array}{l}\text { FALL IN Hb } \\
\text { (gms) }\end{array}$ & $0.49 \pm 0.43$ & $1.54 \pm 0.54$ & 0.003 \\
\hline $\begin{array}{l}\text { BLOOD } \\
\text { TRANSFUSION }\end{array}$ & $1(3.33 \%)$ & $2(6.67 \%)$ & - \\
\hline
\end{tabular}

\section{Discussion}

Galvin DJ et al (2006) ${ }^{3}$ described that Percutaneous nephrolithotomy has replaced open stone surgery for large and complex renal or upper ureteral calculi because it is a minimally invasive technique.

Sukumar S et al (2008) ${ }^{15}$ conducted a study on Supracostal access for percutaneous nephrolithotomy and described that the outcome of PCNL is directly related to an optimal access tract. The majority of stones in the pelvis and mid or lower calyces can be easily reached via a subcostal puncture. However, access to the stones may require an upper pole approach in specific conditions. The indications for a supracostal approach are complex staghorns, upper calyceal stones, upper ureteral stones, multiple calculi in the superior and inferior calyceal groups, and stones in anatomically unusual kidneys. Access through a superior calyx provides a straight tract along the axis of the kidney, and it is associated with excellent visualization of the upper and lower calyces, the pelvis, and the ureteropelvic junction. 
This ability to operate along the long axis of the kidney causes less torque of the rigid nephroscope, thereby reducing the chances of excessive bleeding.

Mousavi-Bahar SH et al (2011) ${ }^{11}$ concluded that despite the high success rates, a major concern in supracostal PCNL is the potential for injury to the pleura or lung. The ideal puncture has been described as one that provides the shortest and straightest access to all calculi, avoids major vessels, bowel and lung, lies along the axis of the calyx and causes minimal parenchymal damage. If we need to make all punctures in the axis of the calyx, it stands to reason that the calyces projecting supracostally should have a supracostal access. With the patient supine and in complete expiration, $58-70 \%$ of middle calyces and 20$22 \%$ of lower calyces were above the rib. Urologists, of course, are more concerned about the site of puncture rather than the calyx. If one draws a straight line from the edge of the calyx to the skin along the axis of the calyx, a large majority in the upper and interpole calyces, will intersect the skin above the $12^{\text {th }}$ rib. These tracks will naturally be supracostal. Golijanin D et al $(1998)^{4}$ concluded that when the supracostal approach is performed, the risk of pneumothorax or pleural effusion requiring drainage is $4 \%$ to $12 \%$. Kekre NS et al $(2001)^{7}$ reported a $9.8 \%$ incidence of pleural collections requiring the intercostal chest tube drainage. Sukumar et al $(2008)^{15}$ suggested that in the case of nephrostomy access between the 11th and 12th ribs, $9.1 \%$ of patients present fluid accumulation within the pleural space. Munver et al $(2001)^{12}$ found that punctures above the 11th rib have a 16-fold greater risk of intrathoracic complications than the supracostal 12th rib access and a 46-fold greater risk than subcostal access. However, Finelli and Honey $(2001)^{2}$ stated that the risk of pulmonary injury with 10th intercostal access is not as high as predicted by radiologic studies provided the puncture is done with the patient in full expiration. Mousavi-Bahar SH et al (2011) ${ }^{11}$ reviewed their complications from supracostal punctures for
PCNL in 123 patients, and pneumothorax was found in only 3 cases (2.4\%). Similarly, Muzrakchi AA et al $(2004)^{13}$ reported complications of PCNL during supracostal 12th rib and supracostal 11th rib access; only 2 patients had minor chest complications in this study. An early CT determined the risk of adjacent organ injury seemed to have added to the fear of the supracostal approach. Hopper KD et al (1990) ${ }^{5}$ reported that the chances of transgressing the lungs in complete expiration were $29 \%$ on the left and $14 \%$ on the right in a supra 12th approach and almost universal in a supra 11th approach. While in our study no adjacent organ injury was reported.

\section{Summary and Conclusion}

Upon conclusion we infer that:

1) Our study comprised of 60 patients, with 30 each in the Supracostal group and Infracostal group respectively.

2) Mean age in supracostal group was $45.30 \pm$ 10.882 years while in the infracostal group it was $44.83 \pm 13.468$ respectively.

3) Male female ratio in the supracostal group was 2:1 while in the infracostal group it was 2.3:1respectively.

4) Both the groups were comparable with respect to age and sex.

5) The site of calyceal puncture in supracostal group was superior calyx in $21(70 \%)$, Middle calyx in $8(26.67 \%)$ and inferior calyx in 1 $(3.33 \%)$ of patients respectively, while in the infracostal group it was superior calyx in 5 (16.67\%), middle calyx in $12(40 \%)$ and inferior calyx in $13(43.33 \%)$ patients respectively

\section{Bibliography}

1. Curhan GC, Willet WC, Rimm EB, Stampfer MJ: Family history and risk of kidney stones. Journal of the American Society of Nephrology 1997a; 8:1568-73.

2. Finelli A. Honey RJ. Thoracoscopyassisted high intracostal percutaneous 
access. Journal of Endourology 2001;15(6):581-584.

3. Galvin DJ, Pearle MS. The contemporary management of renal and ureteric calculi. British Journal of Urology Int. 2006;98(6):1283-1288

4. Golijanin D, Katz R, Verstanding A, Sasson T, Landau EH, Meretyk S. The supracostal percutaneous nephrostomy for treatment of staghorn and complex kidney stones. Journal of Endourology 1998;12(5):403-405.

5. Hopper KD, Yakes WF. The posterior intercostal approach for percutaneous renal procedures: Risk of puncturing the lung, spleen, and liver as determined by CT. American Journal of Roentgenology 1990;154:115-7.

6. James E Lingeman, Brian R Matlaga, Andrew P Evan: Surgical management of upper urinary tract calculi. CampbellWalsh Urology 2007; Volume 2, Ch 44:1434

7. Kekre NS, Gopalakrishnan GG, Gupta GG, Abraham BN, Sharma E. Supracostal approach in percutaneous nephrolithotomy: experience with 102 cases. Journal of Endourology 2001;15(8):789791.

8. Margeret S. Pearle, Yair Lotan. Urinary lithiasis: Etiology, epidemiology, and pathogenesi. Campbell-Walsh Urology 2007; Volume 2, Ch 42: 1363-73

9. Mc Geown MG: Heredity in renal stone disease. Clinical Science 1960; 19:465.

10. Modlin M:A history of urinary stone. South African Medical journal 1980 Oct 18; 58(16): 652-55

11. Mousavi-Bahar SH, Mehrabi S, Moslemi MK. The safety and efficacy of PCNL with supracostal approach in the treatment of renal stone. International Urology and Nephrology. 2011;43(4):983-987.

12. Munver R, Delvecchio FC, et al Critical analysis of supracostal access for percutaneous renal surgery. Journal of Urology 2001;166:1242-6.

13. Muzrakchi AA, Szmigielski W, Omar AJ, Younes NM. Is the 10th and 11th intercostal space a safe approach for percutaneous nephrostomy and nephrolithotomy? Cardiovascular and Interventional Radiology 2004;27(5):503506.

14. Resnick M, Pridgen DB, and goodman HO: Genetic predisposition to formation of calcium oxalate renal calculi. New England Journal of Medicine 1968; 278:1311-18.

15. Sukumar S, Niar B, Kumar PG, Sanjeevan $\mathrm{KV}$, Bhat HS. Supracostal access for percutaneous nephrolithotomy: less morbid, more effective. International Urology and Nephrology: 2008;40(2):263267. 